\title{
AUTONOMIA E EDUCAÇÃO FÍSICA: UMA PERSPECTIVA À LUZ DO IDEÁRIO DA PROMOÇÃO DA SAÚDE
}

Arestides Pereira da Silva Júnior

Ana Lúcia Lago Nakamura

João Carlos Nogueira Louzada

Marília Velardi

\section{Resumo}

O termo autonomia tem sido freqüentemente utilizado na Educação Física de maneira funcional, restringindo seu conceito à operacionalização das ações motoras ou cognitivas que um indivíduo é capaz de realizar de maneira independente. Assim, a autonomia é considerada como sinônimo de independência física e cognitiva e reduzida ao sentido de funcionalidade independente. Desta forma, o propósito do presente trabalho é iniciar discussões e reflexões que incitem a busca de referencial teórico que traga suporte à criação de relações entre Educação Física e o ideário da Promoção da Saúde considerando a autonomia como questão central destas duas áreas. As conclusões dos autores apontam que a autonomia expressa no Ideário da Promoção da Saúde, compreendida especialmente à luz do pensamento filosófico, terá implicações na prática em Educação Física, na busca de meios que nos conduzam ao estímulo da autonomia das pessoas.

\section{Palavras-Chave:}

Autonomia; Educação Física; Promoção da saúde.

\section{AUTONOMY AND PHYSICAL EDUCATION: A PERSPECTIVE IN THE LIGHT OF THE IDEAS OF THE HEALTH PROMOTION}

Arestides Pereira da Silva Júnior

Ana Lúcia Lago Nakamura

João Carlos Nogueira Louzada

Marília Velardi

\begin{abstract}
The term autonomy has been frequently mentioned in Physical Education, which in many cases is used in a functional way, restricting its concept to the motor or cognitive actions that a person is able to perform in an independent way. Thus, autonomy is constantly considers as a synonym of physical and cognitive independence. The purpose of the present paper is to begin discussions, reflections that conduce us until a theoretical referential that shows the importance of autonomy in Physical Education in the light of Health Promotion. That authors conclusions that autonomy in Health Promotion should be applied in Physical Education as a Key tool, leading people to reflect upon the management of their actions.
\end{abstract}

\section{Key-Words:}

Autonomy; Physical Education; Health promotion. 


\section{Introdução}

$\mathrm{O}$ termo autonomia vem sendo freqüentemente utilizado em nosso cotidiano e com bastante importância na área da Educação Física. Entretanto, a utilização do termo autonomia parece, muitas vezes, distanciar a palavra de seu significado, de seu conceito, já que existe uma grande confusão entre o entendimento da diferenças entre autonomia e independência física. Normalmente atribui-se o significado de autonomia à independência, que é caracterizada pelo desempenho satisfatório das capacidades funcionais (físicas e cognitivas), ou seja, quando uma pessoa não precisa de auxílios externos, ou ainda utiliza pouco auxílio para realizar suas atividades do cotidiano.

Em relação a isso Farinatti (2000) em seu estudo sobre autonomia, revela que este termo é frequentemente apresentado por meio de duas abordagens, sendo uma eminentemente negativa, caracterizada pela "perspectiva medicalizada" e outra num prisma plurifatorial e positivo, tendo o ideário da "Promoção da Saúde" como representante.

A autonomia vista pelo paradigma biomédico caracteriza-se por uma abordagem negativa e confunde-se com a idéia da independência física. Neste sentido, seu enfoque principal está na ausência das incapacidades e tratada de forma restritiva, relacionada à execução de tarefas predeterminadas. Farinatti (2000) define, então, que o indivíduo é autônomo por exclusão, a partir da noção de dependência. O indivíduo é considerado autônomo quanto menos graves sejam as implicações sobre a sua dependência funcional.

Emerge, então, uma questão que nos parece bastante primária: será que o fato de uma pessoa realizar uma tarefa do seu cotidiano ou qualquer atividade física sem auxílio ou com independência é suficiente para considerá-la como autônoma? O que, de fato representa este termo?

Para Farinatti (2000), a autonomia foi definida como um conceito que pode ser considerado um estado de arte. Isso significa que parece ser mais fácil definir e conceituar autonomia quando ela se apresenta num determinado contexto, associando sua compreensão aos diversos domínios do conhecimento e integrando muitas dimensões. Considera-la desta forma implica, inclusive, pensarmos que o exato conteúdo da autonomia bem como o limite da autonomia moral encontram-se, possivelmente, em aberto (HOLM citado por ALMEIDA, 1999). 
Apropriando-nos de um outro referencial teórico que se opõe ao tradicional paradigma biomédico que há muito subsidia a área da Saúde, encontramos maiores reflexões frente ao conceito de autonomia. Na perspectiva da Promoção da Saúde, a idéia de autonomia pauta-se na associação deste conceito não apenas com os obstáculos associados à dependência física ou social, significando que este termo não se relaciona apenas ao viver de maneira independente (VELARDI, 2003). Assim sendo, a autonomia deve ser considerada decorrente de algo que transcende as ações cotidianas, que se relaciona à capacidade de realização pessoal.

No ideário da Promoção da Saúde, a autonomia é entendida através do paradigma biopsicossocial da saúde, ou seja, em oposição à preocupação tradicional de curar ou prevenir enfermidades, além da capacidade de realizar ações com independência. Nesta perspectiva o desenvolvimento da autonomia se dá por meio da capacitação dos indivíduos e comunidades, por meio do aumento do seu nível de conhecimento e informação, bem como do incremento das condições para que escolham modos de vidas saudáveis. Além disso, pode-se considerar a autonomia como um dos objetivos fundamentais do ideário da Promoção da Saúde (FARINATTI, 2000).

Dessa forma, a autonomia está no centro das estratégias da Promoção da Saúde (CZERESNIA, 2003; FARINATTI, 2000) e, assim sendo, considera-se que a educação é o principal fator contribuinte para fazer com que as pessoas tomem consciência de si e reflitam sobre suas ações para que possam lidar melhor suas decisões (FREIRE, 2002).

Para sua melhor compreensão, Farinatti (2000) classifica a autonomia em três níveis, ao mesmo tempo distintos e interligados: uma "autonomia de ação", uma “autonomia de vontade" e uma "autonomia de pensamento". Segundo o autor a "autonomia de ação" incorpora a noção de "independência física", passando pela possibilidade de se mover sem entraves, sem obstáculos materiais, sem constrangimentos físicos. O indivíduo deve gozar de auto-suficiência que lhe permita satisfazer suas necessidades e desejos. A "autonomia de vontade" corresponde às possibilidades de "autodeterminação". O indivíduo deve poder escolher, sem influências ou pressões coercitivas. A “autonomia de pensamento” é o nível mais profundo da autonomia, pois ela representa a diferença entre "autonomia e liberdade", a consciência que nos permite julgar uma situação qualquer. 
Esta classificação apresentada pelo autor traz uma relação com outros termos que são diferentes do conceito de autonomia, mas que, ao mesmo tempo são importantes para sua caracterização. Entretanto, esta definição gera alguns questionamentos. $O$ sentido do termo autonomia pode ser dissociado $e$ dividido dessa forma? Em que medida, segundo a divisão apresentada, um nível de autonomia será possível sem o outro?

Assim, é importante considerarmos que a autonomia dos indivíduos é influenciada por fatores externos, como a interferência de outras pessoas nas suas decisões pessoais, dependência de outros para realizar alguma atividade, fatores econômicos, sociais e políticos.

A partir desta problemática complexa envolvendo a utilização do termo autonomia, surgem algumas inquietações: Qualquer tomada de decisão da pessoa pode ser considerada expressão de autonomia? Como a Educação Física pode levar as pessoas ao desenvolvimento e ao exercício da autonomia? Como a educação influencia na conquista da autonomia? Entretanto, todos estes questionamentos só poderão ser respondidos se nos debruçarmos sobre uma questão inicial: Qual seria o significado de autonomia?

Desta forma, o propósito do presente trabalho é discutir, refletir e apresentar um referencial teórico que traga suporte à criação de relações entre Educação Física e o ideário da Promoção da Saúde considerando a autonomia como questão central destas duas áreas. Busca-se ir além da utilização do termo, caminhando para a compreensão do conceito e sua adequada utilização. Este ensaio será, então, fundamentado a partir de uma análise de estudos filosóficos que auxiliarão no entendimento do conceito de autonomia, o que abrirá caminhos para a busca das respostas às outras indagações.

Portanto, para a compreensão do significado da autonomia torna-se necessário um esforço na compreensão dos caminhos históricos, filosóficos e dialéticos para a análise deste trajeto.

\section{A Autonomia e o Pensamento Filosófico: A Formação de um Conceito}

Quando falamos em autonomia é indispensável que tenhamos um alicerce filosófico para sustentar este princípio, pois há muito tempo esta questão tem sido o cerne das discussões filosóficas.

A palavra autonomia é de origem grega, composta pelo adjetivo pronominal autos, que significa ele mesmo" e "por si mesmo"; e pelo substantivo nomos, com o sentido de "compartilha", "instituição", "lei", "normas", "convenção" ou "uso". Etimologicamente, o conceito de autonomia significa "a condição de 
uma pessoa ou de uma coletividade autônoma, quer dizer, que determina ela mesma a lei à qual se submete" (LALANDE, 1996. 115).

A Filosofia compreende a autonomia como uma capacidade humana que envolve a produção de juízos que surgem de informações obtidas no meio sociocultural e político (LIMA, 2000). O conceito de autonomia tinha idéia de liberdade e igualdade no passado e até hoje em dia é visto desta maneira (DWORKIN, 1989), mas existem várias abordagens que ampliam as significações do conceito, sendo: auto-determinação, dignidade, integridade, individualidade e intimidade, independência, responsabilidade e auto-conhecimento (BENSON, 1983; DWORKIN, 1989). Para tentarmos entender um pouco desta complexidade da autonomia, vamos recorrer a dois filósofos, Hume e $\mathrm{Kant}^{1}$ que já em meados do século XVIII faziam relações entre valores e autonomia.

Muitos fatores estão relacionados e têm interferência direta no processo da autonomia. Schneewind (2001), afirma que Hume deixa clara sua posição de que a religião é moral e politicamente prejudicial à felicidade humana. Segundo a visão de Hume a religião, como princípio dogmático, subordina as pessoas, caracteriza-se como algo que as prende e, desta forma, aqueles que são subordinados seguem as regras que são consideradas leis. Podemos considerar que Hume apresenta estas reflexões ainda não definindo o termo, mas apontando a relação que há entre autonomia e insubordinação à moral religiosa ou ao dogmatismo.

Hume tenta extrair a religião da moralidade sugerindo que assim as pessoas poderiam investigar sobre algo que incomoda, refletir sobre as ações da sociedade e as suas, questionar as coisas para tentar melhorá-las e não ficar subordinado a leis que são consideradas superiores. Para Hume, a religião é um mal aos homens. Assim como a religião, as regras da sociedade afetam o comportamento das pessoas, pois a toda hora elas são influenciadas a tomarem atitudes impostas por algo julgado superior, que não permite que estas pessoas reflitam sobre suas ações e ajam conforme suas próprias leis, guiadas pelos nossos desejos. Os desejos e paixões não são racionais, segundo Hume, mas devem ser aquilo que nos move. Por sua vez a razão não pode diretamente guiar ou controlar o que fazemos.

De acordo com Hume a moralidade nos move para a ação. Para ele a lei moral não pode estar destinada a nos mostrar o que não podemos fazer (SCHNEEWIND, 2001). Entretanto, a aprovação e a desaprovação 
moral estão envolvidas na produção do nosso comportamento. Assim, Hume oferece seu pensamento como uma explicação para os nossos julgamentos morais, ele parece nos apontar para dois importantes aspectos que marcam a autonomia: julgamento moral - o julgamento dos outros, o patrulhamento, o policiamento e a moralidade - os dogmas, as "Verdades".

Outro filósofo que nos auxilia a compreender os fundamentos da autonomia é Kant, filósofo alemão que nasceu em 22 de abril de 1724 em Könisberg e passou a sua vida toda dedicada ao estudo, foi professor de várias disciplinas na universidade, quanto as suas obras foram muitas importantes na Filosofia, tendo destaque para Kritik der reinen Vernunft (1781) (Crítica da razão pura). A primeira formulação sistemática do conceito de autonomia aplicado ao indivíduo, deve-se a Kant, para quem o sujeito moral em questão é a pessoa, isto é, o indivíduo racional e livre, e é por isso que a ética kantiana será conhecida como "racionalismo ético". Kant afirma que a lei moral autônoma é aquela que tem na "vontade boa" seu fundamento e legitimidade, sendo o único princípio fundamental a moralidade. Se contrapõe à heteronomia embasada na "vontade má" e na irracionalidade.

Aponta a idéia de autonomia voltada ao autogoverno, em que as questões sociais e os valores são peças fundamentais para a construção deste conceito. A idéia de autogoverno em Kant está relacionada à tomada de consciência. Na idéia de autogoverno está implícita a noção de que a pessoa tem o poder de decidir sobre suas ações, estruturar metas que ache condizentes com os seus ideais, para que possa cumpri-las. Em síntese, é governar as suas decisões. O realismo é mais evidente em Kant, pois ele apresenta na sua fundamentação exemplos mais simplificados e que aparecem com mais freqüência no cotidiano. Explicar a moralidade foi um de seus objetivos.

Criar leis que possamos cumprir com a finalidade de vivermos bem é o que sintetiza a relação entre seus ideais da moralidade construída como autonomia. A moralidade é identificada com a necessidade objetiva que não se pode apoiar em quaisquer vantagens que o ato produza (SCHNEEWIND, 2001).

Destacando a razão, Kant diz que ela está apta para produzir as necessidades requeridas nas leis do mundo. Já os sentimentos, especialmente nossos sentimentos corrompidos, variam demais de pessoa para pessoa e de época para época para serem a fonte da ordem moral (SCHNEEWIND, 2001).

\footnotetext{
${ }^{1}$ Quando referenciamos Hume e Kant em todo o texto, seus pensamentos foram extraídos da obra de SCHNEEWIND, J. B. In: A invenção da autonomia, 2001.
} 
A ética kantiana permanece praticamente até Nietzsche, que em Além do bem e do mal e A genealogia da moral (ambos de 1887) descronstrói o racionalismo kantiano. Para o filósofo, como atrás da vontade boa e dos princípios morais racionais agem, motivações inconscientes especialmente a vontade de poder, assim como o ressentimento resultante da frustração da vontade de poder e que de alguma forma determina a influência das religiões frente às pessoas.

A construção do conceito de autonomia é contínua e a Filosofia auxilia através de muitos autores que nos permitem que busquemos, em suas obras, subsídios para reflexões sobre o conceito (ou metaconceito?) de autonomia. Entretanto, algo que parece claro é que quando as sociedades aspirarem e chegarem à autonomia provavelmente haverá mais justiça, em face da necessária e presente responsabilidade para decidir sobre as ações.

\section{O Papel da Educação Para a Autonomia}

A educação representa, em essência, meios de capacitar e auxiliar na formação humana das pessoas. Ou seja, um indivíduo que tem oportunidade de receber informações necessárias para estabelecer a consciência crítica tem o poder de analisar melhor a si e ao seu mundo e, assim, poder escolher o que é mais favorável para a sua vida. Desse modo, estará apto para contribuir no processo de uma sociedade mais democrática. O aprendizado que conduza à consciência crítica poderá influenciá-lo em todas as situações, por toda sua vida e por este motivo, a valorização da educação critizadora deve se dar desde cedo.

Considerando o método educacional freireano, a pedagogia é concretizada na forma de trabalho educativo, no estímulo à discussão, ao diálogo crítico e critizador. O método criado por Paulo Freire se baseia na relação dialógica entre os atores da aprendizagem, tanto alunos quanto professores. Segundo Freire (2001) é através do diálogo que se dá a verdadeira comunicação, em que os interlocutores são ativos e iguais. A comunicação é uma relação social igualitária, dialogal, que produz conhecimento (PEREIRA, 2003). Compartilhando desta idéia Velardi (2003, p. 53), diz que, para Paulo Freire:

A perspectiva educacional que pode ser coerente com a busca da autonomia é aquela que atribui ao educador a função de instaurar o rigor do método, em função de despertar a curiosidade, aquela que estimula a busca constante do conhecimento. Desta forma, a educação assume um caráter de não submissão e então, por extensão, formadora do senso crítico. Aprender criticamente é, em suma, formar a autonomia.

Investir nesse tipo de educação da população, segundo Freire (1996), é a melhor opção para que as pessoas possam exercer sua autonomia e, desta forma, decidam o que é melhor para si, analisando com 
liberdade e direito de escolha. A personalidade, o caráter, os valores individuais são características que as pessoas têm e que influenciam diretamente no processo da autonomia, seja ela individual ou comunitária. Sobre a educação para a autonomia Velardi (2003, p. 55) afirma que:

Será, provavelmente, aquela que define como função social do ensino a formação integral das pessoas como cidadãos e cidadãs ativos da sociedade, o que implica uma ampliação das capacidades a desenvolver (não exclusivamente as acadêmicas) e a correspondente consideração de conteúdos de aprendizagem, não só os tradicionais conteúdos conceituais, mas, também, os procedimentais e atitudinais.

Por este motivo, Paulo Freire (2002), apresenta uma proposta de educação que tenta a passagem da transitividade ingênua à transitividade crítica, em que as pessoas tomem consciência de quem são e do que representam para a sociedade, sendo estimuladas a exporem suas idéias e reivindicando seus direitos na construção de uma sociedade mais democrática.

Para Vieira Pinto (1960), a síntese dos conceitos de consciência crítica e ingênua propostos por Paulo Freire é o ponto de partida para a reflexão de processos educativos e suas intenções. A consciência critica é a representação das coisas e dos fatos como se dão na existência empírica. Nas suas correlações causais e circunstanciais. Já a consciência ingênua, pelo contrário se crê superior aos fatos, dominando-os de fora e, por isso, se julga livre para entendê-los conforme melhor lhe agradar.

O processo de capacitar pessoas se faz presente no modelo de educação proposto nos ideais freireanos, pois a partir daí as pessoas desenvolveriam condições de tomarem iniciativas para conquistarem seus objetivos e não ficarem dependente apenas das soluções advindas dos governantes ou, ainda, desenvolveriam suas capacidades e argumentos para exigirem, construírem e/ou cobrarem soluções para os problemas: "As decisões devem ser do indivíduo e ele tem de ser considerado capaz de tomá-las" (BYDLOWSKI et al., 2004, p. 20). Num momento em que a decisão seja do sujeito, com base numa ação autônoma, haverá certamente implicações sobre a sociedade, que sendo reflexo da autonomia dos indivíduos constituir-se-à numa perspectiva mais democrática. Mas esta capacidade que os indivíduos tomam não depende apenas do conhecimento, mas sim também da possibilidade de conseguir expor seus ideais.

Ter capacidade para colocar-se frente as mais diversas situações, considerando o uso das ferramentas (sejam elas a linguagem, as ações ou o próprio conhecimento) significa ter poder para comunicar-se, posicionar-se e lidar com o meio. Para que uma pessoa esteja "empoderada" (aqui se pode considerar o 
termo em inglês empowerment) é fundamental que, primeiramente, ela se conheça e tome consciência disso, tenha consciência crítica sobre os aspectos que influenciam a sua vida, buscando meios para exercer o controle sobre os determinantes do seu viver. $\mathrm{O}$ indivíduo deve saber quem ele é, identificando seus limites e possibilidades. Tudo isso é muito importante para que ele consiga desempenhar suas tarefas sabendo das suas impossibilidades e potenciais, garantindo, desta forma, uma posição de administrar a sua vida com o que tem e podendo melhorar suas condições de bem viver.

Sen (2000), compartilha com esta idéia de capacitação para o reconhecimento de suas necessidades e tomadas de decisões, afirmando que a educação pra a autonomia fornece às pessoas subsídios para refletirem sobre tudo que fazem e, assim, poderão se qualificar, o que terá impacto sobre toda a sociedade. De acordo com Freire (1996), a educação ideal para este processo seria aquela que levasse o homem a posições "inquietistas", ouvindo, perguntando, investigando e, assim, moldando em sua personalidade uma característica crítica que auxiliará em todas as escolhas de sua vida. Desta forma, acredita-se que a sociedade seria mais justa e democrática, pois as pessoas analisariam suas ações num "todo coletivo" e não pensando somente em levar vantagem sobre os outros, num "pensamento individualista e capitalista”.

Nesta perspectiva de mudança, é necessário que cada pessoa faça a sua parte e não fique esperando de braços cruzados ou de soluções que "caiam do céu". Todos devem ser capazes de interpretar o que é certo e o que é errado e, assim, cobrarem e solicitarem mudanças aos órgãos públicos, governos, políticos, não esquecendo de fazer o que é cabível a ele desempenhar.

Em relação às barreiras que são encontradas quando se pretende fazer mudanças Bydlowski et al. (2004, p. 21) diz que ainda perpetua "uma situação de domínio sobre a população, com a preservação dos interesses de grupos hegemônicos detentores do poder cujas atitudes são voltadas para a manutenção de suas condições privilegiadas, inviabilizando qualquer mudança que coloque em risco tal situação”.

A mudança de atitude em busca de ações que valorizem a reflexão e estimulem a criticidade é fundamental para o processo de mudança na sociedade. Por isso que a valorização de cada indivíduo, dando oportunidade de sua manifestação e sua participação nos processos de decisões tem grande importância para a construção de uma sociedade mais democrática. 
Neste sentido, ensinar não significa transferir conhecimento, mas criar as possibilidades para a sua construção ou a sua produção. O professor ideal não é aquele que expõe o conteúdo aos educandos, mas sim aquele que leva ao aluno a capacidade de compreensão através da reflexão e interpretação (FREIRE, 1996).

Com essa afirmação de Freire pode-se identificar o forte da perspectiva construtivista para uma educação para a autonomia. O construtivismo é a idéia principal do discurso educacional freireano, cuja idéia pauta-se na consideração e utilização dos conhecimentos prévios e cotidianos das pessoas como referência para a construção, formulação e implantação de um novo conhecimento, que seja socialmente necessário para a libertação do indivíduo e para a construção de um fazer e pensar autônomos.

Por um lado, o construtivismo sempre foi alvo de críticas, pois alguns pensadores não conseguem estabelecer um elo entre uma aprendizagem em que o aluno seja formador e construtor do conhecimento. Entretanto, esta perspectiva de aprendizagem é fundamental para a transformação no modo de pensar das pessoas, já que é capaz de levar à reflexão e interpretação dos fatos criando, desta forma, possibilidades de escolhas de vida, aliando, conduzindo à autonomia (PEREIRA, 2003).

Assim sendo, necessitamos de uma reforma urgente e total nas políticas e práticas educativas, na busca de reformas que atingissem desde a organização das instituições até a pratica educativa e, principalmente, o modo de ensinar dos mestres. Transpondo esta perspectiva para a área da Educação Física, isso significa que a prática da atividade ou exercício físico não deve ser meramente repetitiva e sem relação com aquilo que estes conceitos representam para os sujeitos, sua história e seu meio político e social. Além disso, deve ter como ponto de partida o incentivo à reflexão e afinidade do praticante.

Todo este referencial abordado no discurso freireano em relação à educação pode ser considerado como um meio coerente de atuação dos profissionais de Educação Física. Educar é o objetivo primordial da Educação Física. Assim, certamente pode-se considerar contraditória a imposição de um modo de agir (ou a obrigação imperativa da prática de atividades físicas e exercícios) não como uma conquista ou um prazer numa relação direta com a autonomia e a capacidade de escolha e a autodeterminação dos sujeitos, mas como um remédio, com uma mesma posologia para tudo e para todos. 
Autonomia, Educação Física e Promoção da Saúde: Da Utilização de um Termo à Operacionalização de um Conceito.

A autonomia vista da concepção da Promoção da Saúde se dá pela ênfase no desenvolvimento da capacitação ou empowerment dos indivíduos e comunidades, pela utilização de práticas educativas que possam criar ambientes favoráveis para que a população tenha direito à informação, proporcionando habilidades para viver melhor, bem como oportunidades para fazer escolhas mais saudáveis, que direciona a idéia de autonomia (BUSS, 2003; CZRESNIA, 2003).

Nesta perspectiva a Educação Física nos parece melhor contextualizada se considerada como área eminentemente pedagógica, fornecendo condições de acesso das pessoas às informações para interpretálas e exercerem sua autonomia. Como afirmou Azevedo (1999), observar o princípio de básico da autonomia implica, ainda que minimamente, no reconhecimento do direito do indivíduo de compreender o mundo a sua própria maneira, de fazer escolhas, de poder agir de acordo com valores e crenças pessoais".

O termo autonomia, tanto em relação ao ensino quanto à saúde, de acordo com Velardi (2003), está amplamente relacionado à Promoção da Saúde, pois a autonomia é um de seus constructos básicos e, portanto, é fundamental para que as ações dos indivíduos e comunidade (quer sejam de interesse individual quer sejam de interesse coletivo) sejam levadas a cabo. Nesse sentido, a Promoção da Saúde coloca a educação como uma forma de desenvolver o exercício da cidadania para estimular atitudes que levem à melhoria das condições de saúde e vida (BYDLOWSKI et al. 2004).

Na busca de referenciais que nos dêem suporte para a viabilização de práticas em Educação Física que caminhem, na perspectiva da saúde, para uma educação para a autonomia, encontramos nos ideais de Paulo Freire similaridade com muitos dos princípios do ideário da Promoção da Saúde. Entretanto, nos referimos á perspectiva da Promoção da Saúde que se fortaleceu a partir da segunda revolução epidemiológica e que estão sendo expressos desde a publicação da Carta de Ottawa em 1986 (AERTS et al., 2004), que são a autonomia e empowerment.

A Carta de Ottawa define Promoção da Saúde como "o processo de capacitação da comunidade para atuar na melhoria da sua qualidade de vida e saúde, incluindo uma maior participação no controle deste processo" (BRASIL, 2002 p.19). Foi divulgado na Carta de Ottawa que o termo Promoção da Saúde está 
associado a um "conjunto de valores": vida, saúde, solidariedade, equidade, democracia, cidadania, desenvolvimento, participação e parceria, entre outros. A partir destes fatores apresentados começamos a compreender e a modificar o entendimento inicial e errôneo da Promoção da Saúde. Normalmente conceituamos saúde num paradigma biomédico, em que ela é entendida exclusivamente como ausência de doenças, dando a idéia de reducionismo e negativismo (CAPRA, 1982). Mas o entendimento deste conceito é muito mais amplo e deve ser exposto de forma positiva e com uma facilitação para a participação de todos, com a finalidade de mudanças na vida dos indivíduos e no seu ambiente a partir de suas capacidades, necessidades e desejos.

Para a Promoção da Saúde todas as pessoas devem participar do processo de construção da sua autonomia e empowerment, não sendo apenas objetos de soluções paternalistas que tiram sua liberdade e a autonomia nas tomadas de decisões e escolhas sobre seus modos de viver. Para isso a educação é fundamental no processo de empowerment, que uma vez consolidado se manifesta tanto nas esferas individual quanto comunitária. Freire (2002, p. 96), ainda sobre o processo de empowerment da população, diz que: "necessitávamos de uma educação para a decisão, para a responsabilidade social e política".

Neste sentido, a Educação Física por meio dos professores ou profissionais desta área, deveria proporcionar uma educação voltada para o empowerment e não centrar-se apenas em soluções paternalistas, impositivas e criadoras de relações de mútuas dependências entre profissionais e alunos ou clientes. Desta forma, o processo de capacitar as pessoas, educando-as para ter escolhas mais saudáveis e assim adquirir um estilo de vida condizente com suas necessidades e desejos é a idéia fundamental desta perspectiva.

Como podemos observar, incorporarmos o ideário da Promoção da Saúde na relação que representa uma responsabilidade que vai muito além da simples operacionalização lingüística. Não é meta promover a saúde no sentido de um verbo seguido de um objeto, como uma ação que conduz, numa ação de casualidade, uma coisa à outra. A idéia da utilização do ideário da Promoção da Saúde compromete-nos com uma educação para autonomia, que se dá pelo empowerment individual (que, considerando a visão de indivíduo como produto histórico cultural sempre será coletivo) e não se restringe à dominação de áreas sobre áreas nem sobre indivíduos, mas se pauta na construção de capacidades coletivas com vistas à emancipação. Não pode ser considerada como prática restrita às ações "medicalizadas" e 
“medicalizadoras" da prevenção de enfermidades, já que o seu enfoque apresenta uma noção pluralista para a consecução de um objetivo comum, qual seja a saúde das pessoas.

Considerando, então, o ideário da Promoção da Saúde que aponta para transformações dos processos individuais de tomada de decisão para que sejam predominantemente favoráveis à qualidade de vida e a saúde e considerando que esta visão pressupõe um conjunto de ações e decisões coletivas que possam favorecer a saúde e a melhoria das condições de bem-estar (BUSS, 2003), a atividade física por si só não pode ser considerada como promotora da saúde das pessoas. Sem dúvida a prática de atividades físicas pode ser considerada uma forma de prevenção do controle de inúmeras enfermidades. Entretanto, uma prática imposta, massificada e sem reflexão não se transformará em nada além de uma prática temporária sem significado. Além disso, sem dúvida, não podemos considerar que a saúde irá melhorar apenas por este motivo. Quando a atividade física é proposta como um remédio, como uma ferramenta para o controle da saúde em seu sentido mais estreito, a prática fica reduzida à prevenção de doenças. O enfoque da Promoção da Saúde é mais amplo e abrangente, pois "não se dirige a uma determinada doença ou desordem, mas servem para aumentar a saúde e o bem-estar gerais” (LEAVELL; CLARCK, 1976, p. 19), numa busca incessante de meio que favoreçam aos indivíduos a atuação e o controle sobre estes fatores.

A partir dessa contextualização e concordando com o propósito de alguns estudos (BAGRICHEVSKY; PALMA, 2005; MIRA, 2003; MOREIRA, 2001), a "comercialização da saúde" e da qualidade de vida por profissionais principalmente os da saúde vem se tornando cada vez mais comum. Em particular quando referimos à Educação Física neste sentido, os profissionais desta área fazem uma relação que predomina a tendência da atividade física associada à saúde, como fenômeno "causa e efeito" (BAGRICHEVSKY; PALMA, 2005).

A intenção de apresentar a atividade física desta forma não é querer de menosprezar os seus benefícios ou ir a favor do sedentarismo, mas sim mostrar que a atividade física e, por conseguinte seus profissionais isoladamente não têm a tão desejada varinha de condão, como muitos gostariam e tentam acreditar.

Bydlowski et. al. (2004), enfatizam que a Promoção da Saúde considera que melhores condições de vida e saúde só são atingidas através da participação da população de maneira ativa, o que pressupõe um relacionamento mais horizontal e menos submisso, compactuando e assemelhando-se à proposta 
freireana. A Promoção da Saúde pretende que situações de paternalismo e assistencialismo sejam progressivamente eliminadas, através da participação efetiva da população.

\section{Considerações Finais}

Como o termo autonomia normalmente é visto e apresentado na Educação Física numa perspectiva prioritariamente direcionada às relações de ações motoras ou cognitivas que um indivíduo é capaz de executar de maneira independente, procuramos neste ensaio apresentar definições que possam facilitar a compreensão mais ampla do termo. A partir das dúvidas geradas neste ensaio, recorrermos essencialmente à Filosofia para fornecer subsídios indispensáveis na caracterização das possíveis respostas.

Consideramos que a autonomia é um termo que depende de outros conceitos para ser compreendido, tais como: liberdade, responsabilidade, igualdade, independência, auto-conhecimento entre outros. Por este motivo talvez não seja coerente classificá-la em níveis, ordens ou tipos, já que neste caso poderíamos erroneamente atribuir o conceito de autonomia a outro valor ou capacidade a ela relacionada. A autonomia refere-se a um conceito exclusivo e único, apesar da dificuldade da conceituação.

Constatamos que a educação para a autonomia com ênfase no empowerment, tanto individual, como coletivo proposta por Paulo Freire é essencial para que os indivíduos tenham possibilidade de gerenciar melhor suas condições de vida, não dependendo sempre de outros para fazer suas escolhas, que neste caso, seriam mais imposições do que escolhas autônomas. Esta perspectiva abordada por Freire é muito coerente com os ideais da Promoção da Saúde, em que a autonomia é um de seus objetivos principais.

Espera-se que este ensaio possa iniciar um debate acerca das dúvidas freqüentes entre os profissionais de Educação Física em relação à utilização do termo autonomia e a sua operacionalização como meta para a Educação Física das populações a quem atendemos. 


\section{Referências}

AERTS, D. AlvES, G. G. LA SALVIA, M. W. et al. Promoção de saúde: a convergência entre as propostas da vigilância da saúde e da escola cidadã. Cad. Saúde Pública, v. 20, n. 4, p. 1020-1028, Jul./ago., 2004.

ALMEIDA, J. L. T. Respeito à autonomia do paciente e consentimento livre e esclarecido: uma abordagem principialista da relação médico-paciente. 1999. 129 f. (Doutorado)- Fundação Oswaldo Cruz, Escola Nacional de Saúde Pública, 1999.

BAGRICHEVSKY, M; PALMA, A. Questionamentos e incertezas do estatuto científico da saúde: um debate necessário na educação física. Revista da Educação Física da UEM, v. 15, n. 1, 2005.

BENSON, J. Who is the autonomous man? Philosophy. v.58, p. 5-17, 1983.

BRASIL. Ministério da Saúde. As cartas da promoção da saúde. Brasília. 2002. Disponível em: <www.saude.gov.br/bvs/conf_tratados.html.>. Acesso em: 15 jul. 2005

BUSS, P. M. Uma introdução ao conceito de promoção de saúde. In: CZERESNIA, D. Promoção da saúde: conceitos, reflexões, tendência. Rio de Janeiro: Fiocruz, 2003.

BYDLOWSKI, C. R.; WESTPHAL, M. F.; PEREIRA, I. M. T. B. Promoção da saúde: Porque sim e porque ainda não! Saúde e Sociedade. v. 13, n. 1, p. 14-24., jan./abr. 2004.

CAPRA, F. O ponto de mutação: a ciência, a sociedade e a cultura emergente. São Paulo: Cultrix, 1982.

CZERESNIA, D. O conceito de saúde e a diferença entre prevenção e promoção. In:

Promoção da saúde: conceitos, reflexões, tendência. Rio de Janeiro: Fiocruz, 2003.

DWORKIN, G. The and practice of autonomy. Cambridge: University, 1989.

FARNATTI, P. T. V. Autonomia referenciada à saúde: modelos e definições. In: Motus Corporis. v. 7 , n. 1, p. 9-45, 2000.

FREIRE, P. Pedagogia do oprimido. 17. ed. Rio de Janeiro: Paz e Terra, 1987.

. Pedagogia da autonomia. 30. ed. São Paulo: Paz e Terra, 1996.

Educação e mudança. 24. ed. Rio de Janeiro: Paz e Terra, 2001.

. Educação como pratica da liberdade. 26. ed. Rio de Janeiro: Paz e Terra, 2002.

LALANDE, A. Vocabulário técnico e crítico da filosofia. São Paulo: Martins Fontes, 1996.

LEAVELL, S; CLARCK, E. G. Medicina preventiva. São Paulo: McGraw-Hill, 1976.

LIMA, L. C. Organização escolar e democracia radical: Paulo Freire e a governação democrática da escola pública. São Paulo: Cortez, 2000. 
MIRA, C. M. Exercício Físico e Saúde: da crítica prudente. In: BAGRICHEVSKY, M.: PALMA, A.; ESTEVÃO, A.; (Org.). A saúde em debate na Educação Física. Blumenau: Edibes, 2003. p. 169-191. MOREIRA, W. W. Qualidade de vida: como enfrentar esse desafio? IN: MOREIRA, W. W. (Org.). Qualidade de vida: complexidade e educação. Campinas, SP: Papirus, 2001.

NIETZSCHE, F.W. Para além do bem e do mal: prelúdio a uma filosofia do futuro. São Paulo: Martin Claret, 2002.

PEREIRA, A. L. F. As tendências pedagógicas e a prática educativa nas ciências da saúde. Cadernos de Saúde Pública, v. 19, n. 5, 2003.

SCHNEEWIND, J. B. A invenção da autonomia. São Leopoldo: Unisinos, 2001.

SEN, A. A liberdade individual como um comprometimento social. In: SEN, A. Desenvolvimento como liberdade. São Paulo: Companhia das Letras, 2000. p. 320-338.

VELARDI, M. Pesquisa e ação em educação física para idosos. 2003. Tese (Doutorado) - Faculdade de Educação Física, Universidade Estadual de Campinas, Campinas, 2003.

VIEIRA PINTO, A. Consciência e realidade Nacional. Rio de Janeiro: ISEB, 1960. 
Arestides Pereira da Silva Júnior

Universidade São Judas Tadeu

Ana Lúcia Lago Nakamura

Universidade São Judas Tadeu

João Carlos Nogueira Louzada

Universidade São Judas Tadeu

Marília Velardi

Universidade São Judas Tadeu 